\title{
O PROBLEMA DA APLICATIO DA NORMA CONSTITUCIONAL E A JUDICIALIZAÇÃO DA SAÚDE NO BRASIL: A EFETIVAÇÃO DOS DIREITOS SOCIAIS VIA POLÍTICAS PÚBLICAS
}

\author{
Claudine Freire Rodembusch ${ }^{1}$ \\ Henrique Alexander Keske ${ }^{2}$
}

\section{RESUMO}

O presente artigo trata do fenômeno da judicialização da saúde no Brasil, a partir do significativo acúmulo de demandas judiciais promovidas pela cidadania ativa, como forma de concretização do direito social fundamental à saúde. Valendo-se de pesquisa bibliográfica e recurso a bancos de dados oficiais, apresenta o percurso doutrinário, a base constitucional e legal, bem como trata das decisões judiciais a essa demanda social como inseridas no contexto de uma política pública judiciária necessária a efetivação de tais direitos, como resposta ao pungente drama existencial humano de acesso aos serviços de saúde.

Palavras-chave: Concretização de Direitos; Direito Fundamental Social à Saúde; Judicialização da Saúde; Políticas Públicas; Política Pública Judiciária.

\section{THE PROBLEM OF THE APPLICATION OF THE CONSTITUTIONAL NORM AND THE JUDICIALIZATION OF HEALTH IN BRAZIL: THE REALIZATION OF SOCIAL RIGHTS THROUGH PUBLIC POLICIES}

\begin{abstract}
This article deals with the phenomenon of the judicialization of health in Brazil, based on the significant accumulation of legal demands promoted by active citizenship, as a way of realizing the fundamental social right to health. Using bibliographic research and the use of official databases, it presents the doctrinal path, the constitutional and legal basis, as well as dealing with judicial decisions to this social demand as inserted in the context of a judicial public policy necessary for the realization of such rights, in response to the poignant human existential drama of access to health services.
\end{abstract}

Keywords: Judicialization of health; fundamental social right to health; realization of rights; public policies; judicial public policy.

\section{CONSIDERAÇÕES INICIAIS}

\footnotetext{
${ }^{1}$ Doutora em Direito pela Universidade Federal de Burgos-Espanha, Mestre em Direito pela Universidade de Santa Cruz do Sul - UNISC, Pós-graduada em Demandas Sociais e Políticas Públicas pela Universidade de Santa Cruz do Sul - UNISC, Advogada, Professora da Faculdade Estácio RS e Bolsista do Programa Pesquisa Produtividade da ESTÁCIO. E-mail: claudinerodembusch@hotmail.com.

${ }^{2}$ Doutor em Filosofia pela Universidade do Vale do Rio dos Sinos - UNISINOS, Mestre em Filosofia pela Pontifícia Universidade Católica - PUC/RS. Advogado. Integrante do Grupo de Estudos de Direitos Humanos e Transformação Social, da Universidade Ritter dos Reis, Núcleo FAPA. E-mail: hiquekeske@ hotmail.com.
} 
A princípio não poderia, muito menos, deveria acarretar qualquer problema a aplicatio das normas constitucionais, nem tampouco da consequente aplicação das leis ordinárias emanadas em consonância com os princípios basilares insculpidos na Carta Política, haja vista o inquestionável pressuposto de que as disposições constantes do texto fundante da República e do Estado Democrático de Direito informam e formatam toda a organização jurídico-política do próprio Estado e da sociedade como um todo que, através de suas instâncias apropriadas de representação democrática, as estabeleceu enquanto tais, em um processo concomitantemente autoconstitutivo. Portanto, o fenômeno da judicialização da saúde se incluiria em uma espécie de "ultima ratio" se as demais instâncias políticas, encarregadas da administração e prestação de tais serviços conseguissem, efetivamente, cumprir com os mandamentos constitucionais e legais, deixando à instância judicial somente aquilo que lhe compete em uma normalidade de resolução de conflitos em lide.

Entretanto, mesmo que não ocorressem distorções nessa estrutura geral, notadamente administrativa e executiva de tais serviços, deve-se sempre considerar a celeridade da dinâmica social, que gera um distanciamento entre as demandas emergentes na sociedade e a base constitucional e legal, devidamente firmadas no ordenamento. No caso em comento, a própria estrutura institucional dos Poderes do Estado, mesmo considerando suas clássicas funções, se vê afligida pela natural morosidade de seu funcionamento, frente ao surgimento de doenças graves, impossíveis de prever, mesmo pelas mais abertas normas estatuídas e mais relevantes princípios a operar no modo de concepções abertas; nem pelas mais eficazes estruturas administrativas prestadoras de tais serviços. Somem-se a essa equação, ainda, as prováveis respostas a essa demanda, levada a efeito pelo desenvolvimento das denominadas tecnociências da área da saúde, gerando permanente inovação para esse enfrentamento. Esse descompasso, evidentemente, acaba por desvelar um drama humano significativo, pois evidencia o sentido mais elevado de nossa condição existencial, qual seja o de proteção da própria vida, da qual decorre e para a qual se dirige, como fim último, o próprio Direito.

O contraponto entre tais entrechoques de posições costuma ser referido à estruturação de políticas públicas eficientes, que visem operar a concretização do direito à saúde, compreendido como direito social fundamental, porque assim se encontra definido nos textos constitucionais e legais, de maneira que o próprio SUS - sistema único de saúde tem sua origem e finalidade inserida nesse amplo contexto e, apesar de quaisquer críticas que se lhe possa dirigir, apresenta uma possibilidade indissociável para a realização e efetivação de 
tais direitos, transformando-o em instrumento de implementação desse bem coletivo, de maneira universal. Entretanto, isto parece não ter sido suficiente, em função das demandas sociais referidas; daí surge o Judiciário, que passa a ser usado como veículo também apropriado para atender à solução ou encaminhamento, pelo menos, do drama existencial em que se transformou o acesso aos serviços de saúde. Por conta disso, desencadeou-se o processo em comento, em que, agora, a judicialização da saúde passa a ser considerada como uma espécie de política pública judiciária, como forma de tentar equacionar essas díspares variáveis surgidas no curso do próprio funcionamento do sistema como um todo.

Especificamente, o problema que motivou a escritura do presente artigo diz respeito às tensas relações que se estabelecem entre os gestores do sistema e os julgadores de tais demandas, mormente quando se consideram as cifras astronômicas de gastos determinados para atender um número restrito de postulantes, que acabam por comprometer o acesso universal aos demais serviços do próprio sistema. Assim, tanto os gestores quanto os julgadores se veem acossados pela carga onerosa de buscar o enfrentamento desse drama humano e existencial, que impacta, pela base, a própria destinação do orçamento público. Já se estruturam como que sistemas paralelos, reunindo os atores sociais e jurídicos que se inserem nesses contextos, como forma de realizar ações conjuntas para dirimir essas circunstâncias, inclusive para diminuir a carga processual e a própria judicialização, pela resolução extrajudicial dos conflitos. Eis o desafio de equilíbrio que se impõe.

\section{DOS FATOS E PRIMEIRAS ANÁLISES DOS DADOS}

O Conselho Nacional de Justiça publica e disponibiliza um banco de dados denominado de Relatório Justiça em Números, em que faz constar a quantidade da movimentação processual anual nos tribunais brasileiros, cujas informações, aqui transcritas, foram organizadas por Clênio Jair Schulze (2020), no que diz respeito a processos envolvendo a judicialização da saúde no Brasil, com base na $15^{\mathrm{a}}$ edição do referido Relatório, apontando que as demandas processuais se referem aos seguintes pedidos: saúde, envolvendo direito administrativo e outras matérias de direito público; e com foco específico no SUS - Sistema Único de Saúde, que tratam de fornecimento de medicamentos e tratamento médico hospitalar, assistência à saúde de servidor público e assistência médico-hospitalar, ressarcimento, reajuste de tabela de preços e convênios médicos, repasse de verbas, 
terceirização e serviços em saúde; além de tratarem dos planos de saúde, via direito do consumidor, fornecimento de medicamentos pelos planos de saúde e serviços hospitalares via direito do consumidor, plano de saúde via direito do trabalho, taxa de saúde suplementar, via direito tributário, doação e transplante de órgãos e tecidos e saúde mental, controle social e conselhos de saúde, hospitais e outras entidades de saúde e, por fim, erro médico. Tais demandas, a seu turno, de natureza cível, não criminal, exprimem os processos ajuizados até $31 / 12 / 2018$ e em trâmite no $1^{\circ}$ grau, no $2^{\circ}$ grau, nos Juizados Especiais, no Superior Tribunal de Justiça, nas Turmas Recursais e nas Turmas Regionais de Uniformização, considerados cumulativamente. A soma de tais demandas revela o problema que ensejou a escritura do presente artigo, sendo eloquente por si só, uma vez que totalizam a cifra de 2.228.531 processos ajuizados (BRASIL, CONSELHO NACIONAL DE JUSTIÇA, 2019). Em função de números tão expressivos, ainda segundo Schulze:

\footnotetext{
A Judicialização da Saúde está consolidada no Brasil. A partir disso, é necessário promover medidas para reduzir o impacto das decisões judiciais, evitando inclusive o ingresso de novos processos, com a resolução extrajudicial dos conflitos e atuação coordenada de todos os atores envolvidos, como Magistrados, membros de Ministério Público, Defensores Públicos, Advogados, gestores em Saúde e toda a Sociedade. (SCHULZE, 2020).
}

Quando se intenta realizar pesquisa sobre o impacto econômico de tais ações, ou seja, sobre os valores com que tais demandas, uma vez pagas, quer pelos municípios, estados e pela União, impactaram a prestação do serviço de saúde no país, se verifica um entrechoque significativo de cifras, capazes de causar grande estranhamento quanto aos possíveis resultados finais. Entretanto, pode-se partir dos dados fornecidos, por exemplo, pela auditoria operacional sobre judicialização da saúde, realizada e publicada pelo TCU - Tribunal de Contas da União, a partir de dados fornecidos pelo Ministério da Saúde e que registram esses informes em um levantamento histórico iniciado em 2008 e que apresenta, então, em 2015, a totalização de mais de um bilhão de reais; conforme consta de Sessão Plenária desse órgão, levada a efeito em 16.08.2017. (BRASIL, TRIBUNAU DE CONTAS DA UNIÃO, 2020). Por sua vez, quando acessados os dados fornecidos pelo informe econômico do TRF/RJ, chega-se à informação de que os gastos do Ministério da Saúde com a judicialização cresceram 4.600\% de 2007 a 2018; porque, de fato, em 2016, esse Ministério despendeu R\$ 1.157.375.425,35 para atender apenas 1.262 pacientes. Estima-se que, em 2018, esse Ministério tenha gasto $\mathrm{R} \$ 1,3$ bilhão para cumprir as decisões judiciais. Os Estados e os 
municípios vêm sendo ainda mais atingidos. Ademais, projeções para 2019 apontam um acréscimo de gastos que pode beirar a casa de 1,4 bilhão de reais. (BRASIL, TRF/RJ, Valor Econômico, 2019).

Retornando-se ao documento que expressa a auditoria realizada pelo TCU, tornam-se impactantes, para esse exame, as informações ali constantes, intituladas "Principais Achados", segundo as quais o controle administrativo sobre as ações judiciais referentes à saúde é insuficiente no Ministério da Saúde e na maioria das Secretarias de Saúde Estaduais, selecionadas para análise. Além disso, não há procedimentos para detecção de fraudes, à exceção do sistema S-CODES da Secretaria de Estado de Saúde de São Paulo. Em relação a medidas que podem subsidiar o Poder Judiciário na solução das demandas, a auditoria constatou que, entre os nove Tribunais de Justiça pesquisados e os cinco Tribunais Regionais Federais, a maioria não adotou as recomendações do Conselho Nacional de Justiça (CNJ), referentes à judicialização da saúde. (BRASIL, TRIBUNAL DE CONTAS DA UNIÃO, 2020).

Ao se debruçar sobre tais dados, Ana Morozowski, que assina o informe econômico já citado, como membro do Comitê Estadual da Saúde do Rio de Janeiro, posiciona-se no sentido de existir uma absoluta discrepância de decisões judiciais que analisam pedidos de tecnologias de alto custo, o que gera iniquidade e desorganização no sistema, mormente em razão do crescimento exponencial das ações judiciais de saúde e, consequentemente, dos gastos da União, dos Estados e dos municípios com elas. Diante disso, percebe-se que se faz necessário estabelecer um norte ao Poder Judiciário para que haja um mínimo de homogeneidade nas decisões proferidas nas ações que envolvem pedidos de saúde. Em função disso, conclui que:

Também se devem fixar limites à concessão de tecnologias em saúde por decisão judicial, baseando-se nos critérios de custo-efetividade, amplamente utilizados nos processos de incorporação de tecnologias das várias agências existentes em países com sistema de saúde semelhante ao brasileiro. Com o estabelecimento de bases sólidas para a apreciação dos pedidos deduzidos em juízo, é possível evitar a ingerência excessiva do Poder Judiciário nas políticas públicas de saúde, ingerência essa que muitas vezes passa ao largo da análise de questões de orçamento público, bem como dos impactos que uma decisão que concede um tratamento milionário pode gerar nas políticas públicas de saúde já fixadas. (MOROSOWSKI, 2019, p.01).

Em pesquisa realizada pelo INSPER - Instituição de Pesquisa e Ensino (2020) constatou-se, com base no mesmo já citado relatório do $\mathrm{CNJ}$, que dessas demandas, a rubrica 
de acesso a medicamentos implica em mais de $69 \%$ do total de gastos do Ministério da Saúde, razão que acende o sinal vermelho na análise das questões relativas ao orçamento público, haja vista que se referem, em sua totalidade, ao fornecimento de medicamentos extremamente onerosos, para beneficiar vítimas de doenças raras, que reivindicaram ao Judiciário, precisamente, o direito ao recebimento de drogas que não constam na relação daquelas fornecidas pelo SUS. E é aqui que se chocam os dois âmbitos do problema, pois, pelo tratamento estatístico e contábil, se evidencia que vultosos recursos do sistema acabam por ser desviados para somente uma de suas finalidades, deixando ao desabrigo financeiro os demais atendimentos e, logo, a população majoritária que deles necessita, enquanto que, em outro sentido, não estamos a tratar de números e cifras estatísticas, mas de pessoas que, valendo-se de definições constitucionais e legais recorrem ao Judiciário, na última tentativa de ter acesso a tais medicamentos e, dessa forma, recuperar sua saúde e, mesmo, salvar suas vidas, ainda que isto se configure somente como uma expectativa, já que não há certeza absoluta dos resultados a serem obtidos por tais medicamentos.

O trâmite administrativo via SUS, implica no fato de que o sistema deva fornecer os medicamentos que constam do RENAME - Relação Nacional de Medicamentos Essenciais, que também divide as competências entre os âmbitos municipais, estaduais e federal. Além disso, tais medicamentos devem, antes, terem sido aprovados pela ANVISA - Agência Nacional de Vigilância Sanitária. Por fim, tais agentes públicos devem solicitar uma avaliação para outro órgão técnico, a CONITEC - Comissão Nacional de Incorporação de Tecnologias (2020), que fará análises técnico-científicas relativas à eficácia dos referidos medicamentos, para verificar se seus princípios ativos já não estariam atendidos por outros medicamentos disponibilizados, evitando a exploração mercadológica e, ainda, terá que enquadrar tais aquisições levando em conta o impacto econômico em todo o sistema. (BRASIL, MINISTÉRIO DA SAÚDE, 2020). Todo esse trâmite, ainda que correto, evidentemente, demanda tempo e, na maioria dos casos, é disto que tais pacientes não dispõem. Daí o recurso ao Judiciário que, pressionado, acaba liberando o tratamento via liminar, ou no máximo, solicitando laudos periciais, que também demandam tempo. Nesse sentido, pode vir a ocorrer e vem ocorrendo o óbito do postulante de tais demandas.

Por conta disso, e atendendo a recomendações do CNJ, através do Relatório Analítico Propositivo/2019, que trata, especificamente, da judicialização da saúde no Brasil, perfis das demandas, causas e propostas de solução, o próprio Judiciário chama a si a tarefa de 
oferecer contributos ao problema, propondo, no item 6 do referido relatório, subsídios a propostas de políticas, que envolvem a formação de Magistrados, acesso à legislação sanitária e às informações essenciais sobre as políticas de saúde, articulação entre os diversos atores que movimentam a judicialização da saúde, bem como incorporação de novas tecnologias de saúde no sistema público e políticas para a solução extrajudicial de conflitos sobre saúde, além de tratar do papel dos enunciados do próprio CNJ na formação dos Magistrados, na criação de Varas Especializadas e, por fim, a organização e acesso de dados judiciais nos Tribunais. (BRASIL, CONSELHO NACIONAL DE JUSTIÇA, 2019).

Entretanto, cabe ainda destacar matéria assinada por Itamar Melo, enquanto jornalista investigativo, em que publica, no Caderno DOC, do Jornal Zero Hora, de 23/24.11.2019, às páginas 10 e 11,intitulado “O Judiciário Acossado", em matéria de grande repercussão social, uma espécie de desagravo do Desembargador Niwton Carpes, que, no Rio Grande do Sul, está à frente do Comitê Gestor da Judicialização, atendendo às referidas recomendações do CNJ e que reúne o Tribunal de Justiça, a Secretaria Estadual de Saúde, a Federação das Associações de Municípios, os Ministérios Públicos Estadual e Federal, a Advocacia Geral da União, a Procuradoria Geral do Estado e da União e o Conselho Regional de Medicina. Segundo o Magistrado, as reuniões do referido comitê, apesar de tensas, contribuíram para encontrar soluções como formas de diminuir o impacto da judicialização no orçamento público, refreando uma espécie de judicialização desenfreada, embora, no que diz respeito ao atendimento das pessoas desesperadas que recorriam e recorrem ao Judiciário, se deva levar em conta a condição do próprio Juiz, haja vista que: "Essa é uma das piores decisões. O Juiz entra em pânico. A petição inicial vai descrever o fato com um colorido melodramático, vai pintar um quadro de desespero, de pavor, que deixa o Juiz ansioso e aflito. A tendência natural da gente é tentar salvar.” (MELO, 2020, p. 10).

Assim, tais fatos e análises de dados remetem, antes de quaisquer considerações, que estamos a tratar de direitos fundamentais sociais que, insculpidos nas normas constitucionais e legais, visam tutelar o bem máximo do ordenamento, que é a própria vida e, logo, a saúde, como o define o ordenamento, em sua universalidade, com base nos princípios fundantes de nossa ordem jurídica, enquanto Estado Democrático de Direito, pautado, antes de quaisquer outros valores deontológicos, pela dignidade da pessoa humana. Além disso, mostra que, para além de quaisquer definições abstratas do ordenamento, tais direitos somente se podem efetivar por meio de políticas públicas adequadas. Ademais, não somente os postulantes de 
tais demandas, mas todos os operadores do direito se constituem de pessoas, em quaisquer âmbitos em que atuam, afastando-se, assim, do Direito, quaisquer orientações que não digam respeito a essa humana condição. O problema se dá, então, na forma de efetivar tais direitos fundamentais, enquanto concretude na ordem social.

\section{DOS FUNDAMENTOS CONSTITUCIONAIS E LEGAIS E BASE DOUTRINÁRIA}

A origem e o fundamento de todas essas questões suscitadas, diz respeito ao texto constitucional, dado que a saúde se configura como direito fundamental, a partir de sua abrangência universal e integral, atingindo, dessa forma, a todos, em sua proteção, bem como permitindo a todos o exercício de tais direitos, configurados como dever do Estado, conforme preceituam os artigos. $6^{\circ}$ e 196 da C.F./88; que o coloca no rol dos direitos sociais e, de forma explícita, determina a sua garantia, mediante políticas públicas, de cunho social e econômico, capazes de possibilitar o acesso universal e igualitário, para promoção, proteção e recuperação da saúde, incluindo desde o risco de doenças até os seus agravos. Assim, nenhum dos elementos fáticos acima referidos e que acabaram por repercutir no processo de judicialização da saúde, deixam de estar sob a proteção de tais determinações que, ao se configurarem como norma constitucional, como tal devem ser interpretadas e, logo, assumem o caráter de força normativa, cabendo ao Estado e à sociedade como um todo, a busca dos meios necessários a lhe assegurar o máximo de eficácia.

Aí se incluem a constituição das referidas políticas públicas, o trabalho legiferante das casas legislativas para regulamentar as matérias definidas pela Constituição, bem como todas as ações da cidadania ativa no sentido da efetivação de tais direitos, via movimentos sociais e instituições da sociedade civil organizada, onde se inclui, sem dúvida, o acesso à prestação jurisdicional do próprio Estado. Nesse sentido, cabe a afirmação de Eros Grau, segundo o qual:

Deveras, a Constituição do Brasil não é um mero 'instrumento de governo', enunciador de competências e regulador de processos, mas, além disso, enuncia diretrizes, fins e programas a serem realizados pelo Estado e pela sociedade. Não compreende tão-somente um 'estatuto jurídico do político', mas sim um 'plano 
global normativo' da sociedade e, por isso mesmo, do Estado Brasileiro. (GRAU, 2005, Prefácio).

Ainda quanto ao caráter próprio da Constituição, pode-se invocar o processo de sua concreção histórica, a partir da própria evolução jurídico-política das sociedades, ao assegurar, normativamente, a conformação do próprio Estado e da sociedade que a institui como elemento fundante e regulador de todo o contexto do ordenamento, o que se configura como uma cultura jurídico-política a lhe atribuir e assegurar essa normatividade:

\begin{abstract}
A constituição jurídica logra conferir forma e modificação à realidade. Ela logra despertar 'a força que reside na natureza das coisas', tornando-a ativa. Ela própria converte-se em força ativa que determina a realidade política e social. Essa força impõe-se de forma tanto mais efetiva quanto mais ampla for a convicção sobre a inviolabilidade da Constituição, quanto mais forte mostrar-se essa convicção entre os principais responsáveis pela vida constitucional. Portanto, a intensidade da força normativa da Constituição apresenta-se, em primeiro plano, como uma questão de vontade normativa, de vontade de Constituição. (HESSE, 1991, p. 24).
\end{abstract}

Considerando-se, portanto, essa força normativa e, concomitantemente, o enunciado explícito dos princípios fundamentais que formam e informam nossa Constituição e, logo, todo o direito pátrio, a partir da afirmação do Estado Democrático de Direito, pautado, antes de quaisquer considerações, pela dignidade da pessoa humana, infere-se que os direitos fundamentais sociais enquanto abrigados no texto, como o direito à saúde, se inserem no mesmo contexto de força normativa, devendo, igualmente, o Estado e a sociedade, a partir desse fundamento, tratar de sua efetividade, concretizando-os socialmente. Daí se poder afirmar que:

\footnotetext{
Neste sentido, importa salientar, de início, que o princípio da dignidade da pessoa humana vem sendo considerado fundamento de todo o sistema dos direitos fundamentais, no sentido que estes constituem exigências, concretizações e desdobramento da dignidade da pessoa humana e que com base nesta devem ser interpretados. Entre nós, sustentou-se recentemente que o princípio da dignidade da pessoa humana exerce o papel de fonte jurídico-positiva dos direitos fundamentais, dando-lhes unidade e coerência. (SARLET, 1998, p. 120).
}

Entretanto, a definição jurídico-política de nosso Estado repousa, logo, em sua concepção como estrutura tripartite de repartição de competências, o que implica no fato de que, se, na efetivação de tais direitos fundamentais vier a ocorrer um lapso normativo, por força de falta de atuação legislativa, ou de uma ação que venha a ser entendida como contraditória aos princípios constitucionais; e, da mesma forma, se omissões e/ou processos 
administrativos, ínsitos às funções executivas, em todos os âmbitos dos entes federativos, forem entendidos como ameaça ou violação desses mesmos direitos, cabe à função jurisdicional do próprio Estado, decidir tais questões, uma vez provocada pelos instrumentos disponíveis à atuação da cidadania ativa. Mas, mesmo que tais causas não se configurem, o acesso à Justiça se reveste do caráter de universalidade. Daí se poder afirmar que:

Entretanto, e isto é relevante para os propósitos deste estudo, é pela via judicial que é possível a realização dos direitos que estão previstos nas leis e na Constituição, e, naquilo que se entende por Estado Democrático do Direito, o Judiciário, através do controle da constitucionalidade das leis, pode servir como via de resistência às investidas dos Poderes Executivo e Legislativo, que representem retrocesso social ou a ineficácia dos direitos individuais ou sociais. (STRECK, 1998, p.51).

O caso em comento, entretanto, fornece um inconteste significado ao debate acerca da intrínseca relação que se estabelece entre a dinâmica social, em confronto com a capacidade normativa específica do Estado, bem como com a própria capacidade administrativa ou executiva desse Estado, quanto ao cumprimento das disposições constitucionais, haja vista a celeridade com que surgem inovações tecnológicas, precipuamente no caso das biociências, ou ciências da saúde, por sua vez, enfrentando os desafios propostos por enfermidades raras e novas que vitimizam os seres humanos que, como princípio máximo, se constituem no fim do próprio Direito. Com isto se quer significar que nenhuma atividade legislativa, nem mesmo as mais focadas ações administrativas da coisa pública conseguiram dar conta de uma tal celeridade. Daí, também, é que se abre o campo de ação do Judiciário, uma vez provocado para dar resposta a essas aflitivas demandas sociais. Por conta disso, se deve atentar para o depoimento de Bruno Naundorf, que, como Diretor de Auditoria do SUS, da Secretaria Estadual da Saúde /RS ao tratar do tema, na citada matéria do jornalista investigativo Itamar Melo, assim se posiciona:

\footnotetext{
O legislador constituinte se inspirou no melhor sistema do mundo, que é o inglês, mas sem os recursos para isso. Passamos a ter um sistema universal. Só que universalidade não é dar tudo para todos. Universalidade é todos terem acesso. Mas é ter acesso na forma como querem, ou na forma das políticas públicas? A Constituição fala que é mediante políticas públicas instituídas. Não é dar tudo, que seria o princípio da integralidade. É dar o que foi instituído. Quando uma pessoa judicializa, ela quebra a universalidade e a equidade, que são pilares do SUS. Se há duas pessoas na mesma situação e uma obtém na Justiça o direito de ter um medicamento, não dá para dizer que todos terão o mesmo tratamento. (MELO, 2019, p. 08).
} 
Tais afirmações, então, conduzem esse estudo para o fato de que a Constituição Federal/88 pode ser considerada como a matriz jurídico-política com que se intentou introduzir, no país, os fundamentos de um Estado de Bem-Estar Social, baseado, sobretudo, nesse caráter que assumiram as democracias europeias surgidas no Pós-Guerra. Em função dessa configuração do Estado, instituída pela Constituição, o SUS - Sistema Único de Saúde, se constitui em uma das mais expressivas emanações desses princípios formadores, pois, consubstancia-se nos ditames do Art. 198 - C.F/88,que determina integrar as ações e serviços públicos de saúde em uma rede regionalizada e hierarquizada, constituindo-se em um sistema único, obedecendo aos princípios de descentralização, com direção única em cada esfera de governo; atendimento integral, com prioridade para as atividades preventivas, sem prejuízo dos serviços assistenciais; bem como participação da comunidade. A partir desse mandado constitucional, a seu turno, surge a Lei $n^{\circ} 8.080 / 90$, que, em consonância com tais princípios, enfatiza, em seu art. $2^{\circ}$, que a saúde é um direito fundamental do ser humano, devendo o Estado prover as condições indispensáveis ao seu pleno exercício.

Agora, a esteira da discussão se desloca para o campo doutrinário, através do qual se podem expressar os possíveis sentidos e significados para os três princípios constitucionais legitimadores do SUS. Assim, pode-se afirmar que:

\begin{abstract}
A universalidade está ligada à garantia do direito à saúde por todos os brasileiros, sem acepção ou discriminação, de acesso aos serviços de saúde oferecidos pelo SUS. O significado deste princípio é extremamente relevante para a consolidação da democracia, pois, a partir de então, toda a população passa a ter direito de acesso aos serviços de saúde. Outro princípio fundamental é integralidade. Tal conceito parte da ideia de que existem várias dimensões que são integradas envolvendo a saúde dos indivíduos e das coletividades. Assim, o SUS procura ter ações contínuas no sentido da promoção, da proteção, da cura e da reabilitação. Da mesma forma, a equidade como princípio complementar ao da igualdade significa tratar as diferenças em busca da igualdade, reforçando a busca de, pelo menos, minimizar as desigualdades sociais dos indivíduos. (VASCONCELOS; PASCHE, 2006, p. 535).
\end{abstract}

O ordenamento pátrio dispõe, portanto, de sólida base constitucional e legal, que configura o direito à saúde na espécie dos direitos fundamentais sociais, dado que, devidamente positivados na Carta Política e regulamentados, de forma ordinária, pela criação do Sistema Único de Saúde. A análise dos princípios consagrados, quer na fonte constitucional, quer legal, atestam uma sintonia claramente estabelecida no plano normativo, fazendo essa carga principiológica ter sua origem na dignidade da pessoa humana. No sistema específico da saúde, necessário, então, dar efetividade a essa carga normativa e, logo, aos 
referidos princípios de universalidade, integralidade e equidade. Nesse sentido, é necessário atentar para a questão das competências dos Poderes do Estado, notadamente quando se coloca a via judicial como agente solicitado a operar essa concretização de direitos no meio social e, por conta disso, não se pode descuidar a questão da destinação dos recursos financeiros capazes de sustentar essa efetivação de direitos, enquanto demanda social crescente. Essa discussão, agora, envereda, então, para a questão propícia das políticas públicas, enquanto mecanismos hábeis para dar conta de uma aproximação entre as disposições constitucionais e legais, para que não se constituam em letras "mortas" de direitos abstratos, não experienciados enquanto realidades sociais pelos próprios destinatários finais de tais direitos estatuídos.

\section{DO CAMPO ESPECÍfICO DAS POLÍTICAS PÚBLICAS}

Outro percurso doutrinário se coloca como necessário, nesse passo, porque tais declarações, logo, evidenciam a questão de pautarmos algumas considerações acerca dos possíveis sentidos e significados a serem associados à conceituação de políticas públicas, para nos acercarmos mais de nosso objeto de análise, já que podem ser consideradas como o campo notável em que se interrelacionam os âmbitos jurídicos e políticos, principalmente quando se intenta, por meio delas e por determinação constitucional, realizar a efetivação social de direitos fundamentais. Nesse sentido, se posiciona Maria Paula Dallari Bucci, ao afirmar que se constituem em "programas de ação destinados a realizar, sejam os direitos a prestações, diretamente, sejam a organização, normas e procedimentos necessários para tanto.” (BUCCI, 2006, p.31). No mesmo sentido, torna-se relevante considerar, ainda, que política pública se refere a:

Programa de ação governamental que resulta de um processo, ou conjunto de processos juridicamente regulados - processo eleitoral, processo de planejamento, processo de governo, processo orçamentário, processo legislativo, processo administrativo, processo judicial - visando coordenar os meios à disposição do Estado e as atividades privadas, para a realização de objetivos socialmente relevantes e politicamente determinados. (BUCCI, 2006, p. 39). 
A seu turno, Giampaolo Poggio Smanio, em artigo intitulado "Legitimidade jurídica das políticas públicas: a efetivação da cidadania”, afirma que:

\begin{abstract}
Os valores fundamentais adotados pela Constituição Federal transformam-se em princípios gerais de direito e passam a ser a base racional-filosófica para qualquer exercício dos poderes constituídos do Estado. A cidadania, considerada em todas as suas dimensões, é um desses valores, refletida em princípio geral de direito para a atuação do Estado Democrático de Direito. As políticas públicas só ganham legitimidade, portanto, nessa dimensão. (SMANIO, 2013, p. 34).
\end{abstract}

No tocante, ainda, a essa questão da legitimação das políticas públicas, vale ressaltar as afirmações de Clarice Seixas Duarte, em artigo intitulado "O ciclo das políticas públicas", quando insiste que, para se compreender o conceito de políticas públicas, não basta apenas estudar as instituições jurídicas, é preciso estudar o processo político de tomada de decisões e os requisitos necessários para sua legitimidade, de forma que:

[...] para a compreensão do conceito refere-se ao fato de uma determinada política não poder ser considerada pública a menos que seja adotada por uma instituição governamental. Entretanto, pode ocorrer que uma iniciativa bem-sucedida oriunda da sociedade civil acabe incorporada pela Administração Pública e sendo por ela implementada na forma de uma política pública voltada à concretização de um determinado direito. (DUARTE, 2013, p. 18).

Quando trata do tema da legitimidade democrática das políticas pública, por meio de uma análise mediante os pressupostos discursivos da soberania popular, Túlio Cruz Nogueira assevera que esta legitimidade depende da maneira como estas promovem medidas inclusivas, com a fim de efetivarem os direitos humanos e fundamentais, para concretizar o princípio de igualdade, como fundamento das instituições democráticas, de forma que:

Isto demostra a necessidade da atuação conjunta do Direito com as políticas públicas na promoção da igualdade substancial. A relação existe porque uma das características de ampliação do conteúdo jurídico da igualdade é a multiplicação das demandas por direitos, consequentemente, da demanda por políticas públicas. (NOGUEIRA, 2013, p. 113).

No percurso teórico empreendido, no sentido de traçar alguns parâmetros para se compreender a complexidade do fenômeno da judicialização da saúde no Brasil, vale retomar, ainda que brevemente, a ideia de que, quando da busca da efetivação dos direitos sociais fundamentais, como o da saúde, uma vez provocado, o Judiciário não estaria, a princípio, 
usurpando as competências dos demais poderes, ou seja, do Legislativo e/ou Executivo, haja vista que:

\begin{abstract}
A concretização dos direitos sociais pelo Judiciário, condenando a Administração a prover bens e serviços, insere-se nessa rede de implicações recíprocas. Não é possível, portanto, através da simples referência à separação de poderes, deslegitimar a garantia de direitos sociais pelo Judiciário. Pode-se discutir o grau dessa interferência. Pode-se argumentar que a jurisprudência brasileira judicializa excessivamente a política. Essa crítica, contudo, só ganha consistência quando opera com outros elementos, que não simplesmente o princípio da separação de poderes. (SOUZA NETO, 2010, p. 520/521).
\end{abstract}

Em função disso, deva-se considerar correta a afirmação feita por Lucília Alcione Prata (2013, p. 248), no sentido de que o novo "lócus" de formação de políticas públicas de saúde é, precisamente, o Judiciário e, em função disso é que assumem importância na questão da judicialização da saúde no Brasil, os diversos diagnósticos elaborados, nesse sentido, pelo Conselho Nacional de Justiça, enquanto uma nova proposta de política pública judiciária para a saúde, por meio de um de seus máximos órgãos colegiados, em nível federal. E por referirse, então, a uma política pública judiciária, se traz a fala do Ministro Luís Roberto Barroso, no sentido de que:

\begin{abstract}
Judicialização significa que algumas questões de larga repercussão política ou social estão sendo decididas por órgãos do Poder Judiciário, e não pelas instâncias políticas tradicionais: o Congresso Nacional e o Poder Executivo - em cujo âmbito se encontram o Presidente da República, seus ministérios e a administração pública em geral. Como intuitivo, a judicialização envolve uma transferência de poder para juízes e tribunais, com alterações significativas na linguagem, na argumentação e no modo de participação da sociedade. O fenômeno tem causas múltiplas. (BARROSO, 2012, p.24).
\end{abstract}

No momento, portanto, que essa espécie de transferência de poder deixa as esferas legislativas e propriamente executivas e se alça como decisão judiciária, se retoma o tema da estrutura tripartite de poderes, inclusive para tratar dos limites de atuação das políticas judiciárias, sobre os quais também se posicionou o Ministro Gilmar Mendes, destacando, inclusive, as tensas relações surgidas entre os Poderes, considerando a própria capacidade institucional do Judiciário de atender a tais demandas, deslocadas de seu lócus tradicional nas outras esferas políticas:

O fato é que o denominado problema da "judicialização do direito à saúde" ganhou tamanha importância teórica e prática, que envolve não apenas os operadores do 
direito, mas também gestores públicos, os profissionais da área da saúde e a sociedade civil como um todo. Se, por um alado, a atuação do Poder Judiciário é fundamental para o exercício efetivo da cidadania, por outro, as decisões judiciais têm significado um forte ponto de tensão entre os elaboradores e executores das políticas públicas, que se veem compelidos a garantir prestações de direitos sociais das mais diversas, muitas vezes contrastantes com a política estabelecida pelos governos para a área de saúde e além das possibilidades orçamentárias. (GILMAR MENDES, 2010, p. 79/10).

Outro fator relevante na discussão e não poderia deixar de ser, diz respeito, precisamente, à questão do custeio de tais serviços, pois, para além das questões institucionais e definidoras dos âmbitos de atuação própria dos Poderes do Estado e da própria caracterização das políticas governamentais e da destinação dos recursos financeiros para cumprimento de suas metas, deve-se ressaltar, antes de quaisquer considerações, que a fonte e/ou origem desses recursos, os fazem provenientes de recursos públicos; ou seja, foi a própria população que contribuiu para sua constituição como fonte de custeio dos serviços que lhes deveriam ser disponibilizados. Daí a percepção equivocada de uma gratuidade de tais serviços e, até mesmo, um equívoco desse contribuinte, como se não tivesse direito a tais serviços. Por conta disso:

No caso do SUS, o cidadão contribui, obrigatoriamente, por meio de taxas, impostos, tributos, que serão parcialmente alocados ao sistema de saúde (pela esfera federal, estadual e municipal). É o cidadão seu verdadeiro financiador. Embora haja uma percepção, por parte da maioria dos cidadãos, de que o sistema é gratuito (pelo fato de não haver desembolso direito por ocasião do uso ou consumo de produtos e serviços deste sistema). Na realidade, a contribuição é compulsória, não identificável e universal, ou seja, atinge a todos os brasileiros, uns mais, outros menos, mas se caracteriza por uma contribuição de todos. O governo (seja na esfera federal, estadual ou municipal) é, neste caso, gestor do recurso público, além de ser formulador de políticas, regulador e fiscalizador do sistema de saúde. (FERRAZ, 2008, p.26).

Ao discorrer sobre o Judiciário como o novo lócus de formação de políticas públicas no país, Lucília Alcione Prata, em artigo já citado, aponta que essa espécie de ação judiciária, apesar de geradora de tensões, deva ser, antes, compreendida como a busca de eficiência, do próprio Estado, não apenas contribuindo, assim, até mesmo para a diminuição das demandas judiciais, mas, notadamente, para a boa administração e eficiência dos serviços de saúde no Brasil, concluindo, então que:

A atividade judiciária, divergente da atividade judicial que se limita ao julgamento da demanda, implica na convergência do Poder Judiciário ao sistema de proteção 
dos direitos sociais, conjugando esforços, dentro de sua esfera de Estado-juiz, para que não só os princípios de acesso à jurisdição sejam cumpridos, mas especialmente aliando esforços para a fomentação de novas políticas públicas, aptas a garantir a mais ampla proteção jurídica, social e econômica ao direito da saúde dos cidadãos brasileiros. (PRATA, 2013, p. 267).

Não deixa de ser problemática a afirmação de que o processo de judicialização da saúde no Brasil tenha sido capaz de operar, pelo acúmulo de demandas judiciais, ou seja, pelo recurso à via judicial, motivada pela cidadania ativa e sociedade civil organizada, o que se passa a compreender como uma política pública judiciária, mais ampla, portanto, que o de um mero julgamento de uma demanda específica, pois realiza como que uma transferência enorme de poder aos julgadores, em todas as instâncias, que passam a se constituírem em agentes de concretização dos direitos sociais fundamentais, de base constitucional e legal. De pronto, então, isto pode indicar como que inoperância e/ou omissão das demais esferas políticas, sejam legislativas, pela via de representação democrática das casas legislativas, seja pela ação e/ou omissão das diversas instâncias executivas e administrativas da coisa pública. Passa-se, então, a considerar esse processo de judicialização como o de apoio propositivo do Judiciário, no sentido de aperfeiçoar até mesmo a alocação dos recursos de custeio, com a finalidade de que a população-alvo dos serviços de saúde venha a, efetivamente, deles poder usufruir. Eis o problema e o enorme desafio colocado para a efetivação de tais direitos fundamentais.

\section{CONSIDERAÇÕES FINAIS}

Mesmo que se considerem as possíveis omissões legislativas, ou ameaças e efetivas lesões a direitos ou as expectativas de direitos, praticadas por gestores do sistema de saúde, em quaisquer instâncias dos entes públicos, não se pode questionar a legitimidade do Judiciário em ser acionado para a solução de conflitos de interesses inerentes a quaisquer pretensões em lide. Ainda que se possa arguir que essas decisões judiciais venham a ferir a universalidade, integralidade e equidade, como princípios assegurados no ato normativo-legal que institui o sistema, em consonância com as normas constitucionais, não se pode aludir ingerência excessiva do Judiciário, dado que provocado pela cidadania ativa, como instrumento capaz de contribuir para o encaminhamento dessas questões ou enfrentamento 
dessa demanda social específica. Entretanto, o que se deve buscar, sempre, é o ponto de equilíbrio entre as funções gestoras do sistema e, agora, da própria capacidade institucional do Judiciário de dar conta de tal cúmulo de demandas: eis a complexidade do problema.

Se for correto afirmar-se que demandas por direitos equivalem a demandas por políticas públicas, como fenômeno jurídico com origem na própria dinâmica social e se é através de políticas públicas, elaboradas por cada um dos Poderes do Estado e, inclusive, com origem na sociedade civil organizada, desde que incorporadas e/ou encampadas por agentes públicos, a verdadeira legitimidade democrática de tais medidas é o caráter de se constituírem em medidas inclusivas. A questão que se coloca, então, é o fato de a judicialização da saúde no Brasil poder ser considerada ou se inserir no rol das políticas públicas, enquanto uma espécie de política pública judiciária, transferindo esse poder ao Judiciário, como o novo lócus de formação de políticas públicas de saúde em nosso país. Eis o desafio proposto.

Mesmo que se entrechoquem, em tais demandas as arguições de mínimo existencial e, em contraponto, a reserva do possível e, mesmo que se pautem as decisões judiciais por uma espécie de fiscalização do impedimento ao retrocesso, dado que o constituinte originário e ordinário instituíram o direito fundamental e social à saúde, de forma que não se possa voltar atrás no sentido de sua efetivação, nem mesmo diante do fato de se postularem novos direitos agregados a essas disposições estruturantes, deve-se sempre atentar para a questão fundante de que se está a tratar de orçamento público e de recursos de origem pública. Eis, novamente, o problema de se chegar a um equilíbrio satisfatório diante de tal complexidade.

O desafio eloquente, por fim, se reflete no uso de expressões contábeis, como gastos com saúde, totalmente equivocadas, a princípio, quando se volta a considerar o enfoque humano intrinsecamente envolvido em todos os processos: investimentos em saúde, ou direcionamento de recursos públicos para a saúde não se constituem de gastos, mas, sim, da base fundante do próprio Estado, considerando-se a doutrina jurídico-política clássica a embasar a própria constituição do Estado. Entretanto, não é possível desconsiderar o problema da justa distribuição de tais recursos, tocados pela escassez, para dar atendimento ao maior número possível de usuários do sistema, em todas as formas com que se estrutura a prestação de seus serviços de saúde. Aqui, os fins do próprio Estado, bem como dos Poderes que o constituem são colocados à prova e surge o campo precípuo para os operadores do Direito, na busca de soluções para equacionar essa difícil situação existencial. 


\section{REFERÊNCIAS BIBLIOGRÁFICAS}

BARROSO, Luís Roberto. Judicialização, ativismo e legitimidade democrática. Syn]Thesis, Rio de Janeiro, vol. 5, $\mathrm{n}^{\circ}$ 1, 2012, p. 23-32.

BRASIL. Conselho Nacional de Justiça. Justiça em números 2019: ano-base 2018. Brasília: CNJ, 2019. Disponível em: https://paineis.cnj.jus.br/QvAJAXZfc/opendoc.htm?document= qvw_1\% 2FPainelCNJ.qvw\&host=QVS\%40neodimio03\&anonymous $=$ rue\&sheet $=$ shResumoDespFT. Acesso em: 10 mar. 2020.

BRASIL. Conselho Nacional de Justiça. Relatório Analítico Propositivo: Judicialização da Justiça: perfil das demandas, causas e propostas de solução. Disponível em:

http://cnsaude.org.br/wp-content/uploads/2019/07/JUDICIALIZAC\%CC\%A7A\%CC\%83ODA-SAU\%CC\%81DE-NO-BRASIL.pdf. Acesso em: 11 mar. 2020.

BRASIL. Constituição Federal. Disponível em: https://www2.senado.leg.br/bdsf/bitstream/ handle/id/518231/CF88_Livro_EC91_2016.pdf. Acesso em: 10 mar. 2020.

BRASIL. Ministério da saúde. Órgãos técnicos. ANVISA - Agência Nacional de Vigilância Sanitária. Incorporação de novas tecnologias no sistema único de saúde. Disponível em: https://www.saude.gov.br/component/tags/tag/anvisa. Acesso em: 10 mar. 2020.

CONITEC - Comissão Nacional de Incorporação de novas tecnologias no sistema único de saúde. RENAME - Relação Nacional de Medicamentos Essenciais. Disponível em: http://bvsms.saude.gov.br/bvs/publicacoes/relacao_medicamentos_rename_2020.pdf. Acesso em: 11 mar. 2020.

BRASIL. Presidência da República. Casa Civil. Subchefia para Assuntos Jurídicos. Lei No 8.080, de 19 de setembro de 1990. Disponível em: http://www.planalto.gov.br/ ccivil_03/leis/18080.htm. Acessado em: 10 mar. 2020.

BRASIL. Supremo Tribunal Federal. Agravo Regimental. STA, 175. Relator Ministro Gilmar Mendes, DJE 76: 29/04.2010. Disponível em: http://www.stf.jus.br/arquivo/cms/ noticianoticiastf/anexo/sta175.pdf. Acessado em: 12 mar. 2020.

BRASIL. Tribunal de Contas da União. Auditoria operacional sobre judicialização da saúde. Disponível em: file:///D:/Downloads/Judicializa_o-da-sa_de_web.pdf. Acesso em: 13 mar. 2020.

BRASIL. Tribunal Regional Federal 2a Região/RJ. Judicialização da saúde. Valor Econômico, 12 jun. 2019. Disponível em: https://www10.trf2.jus.br/comite-estadual- desaude-rj/judicializacao-da-saude-valor-economico-12619/. Acesso em: 12 mar. 2020.

BUCCI, Maria Paula Dallari. O conceito de política pública em Direito. In: BUCCI, Maria Paula Dallari (org.). Políticas públicas: reflexões sobre o conceito jurídico. São Paulo: Malheiros, 2006. 
DUARTE, Clarice Seixas. O ciclo das políticas públicas. In: SMANIO, Gianpaolo Poggio; BERTOLIN, Patrícia Tuma Martins (Orgs.). O Direito e as políticas públicas no Brasil. São Paulo: Atlas, 2013, p. 16 a 46.

FERRAZ, Marcos Bosi. Dilemas e escolhas do sistema de saúde: economia da saúde ou saúde da economia? Rio de Janeiro: Medbook, 2008.

GRAU, Eros Roberto. Canotilho e a constituição dirigente. Rio de Janeiro: Renovar. 2005.

HESSE, Konrad. A força normativa da constituição. Porto Alegre: Sérgio Antônio Fabris Editor, 1991.

INSPER. Judicialização da saúde dispara e já custa R $\mathbf{R} 1,3$ bi à União. Disponível em: https://www.insper.edu.br/conhecimento/ direito/judicializacao-da-saude-dispara-e-ja-custa-r13-bi-a-uniao/. Acessado em: 11 mar. 2020.

MELO, Itamar. A Saúde na balança do Judiciário. Jornal Zero Hora. Caderno DOC, 23/24 nov. 2019, p. 06-11.

MELO, Itamar. O Judiciário acossado. Disponível em: https://gauchazh.clicrbs.com.br/ saude/noticia/2019/11/o-juiz-entra-em-panico-diz-desembargador-sobre-processos-quebuscam-a-obtencao-de-medicamentos-ck3aby1dd02jo01mq0ev5ed6e.html. Acessado em: 13 mar. 2020.

NOGUEIRA, Túlio Cruz. Legitimidade democrática das políticas públicas: uma análise mediante os pressupostos discursivos da soberania popular. In: SMANIO, Gianpaolo Poggio; BERTOLIN, Patrícia Tuma Martins (Orgs.). O Direito e as políticas públicas no Brasil. São Paulo: Atlas, 2013, p. 96-116.

PRATA, Lucília Alcione. Um novo lócus de formação das políticas públicas de saúde: o diagnóstico da saúde pela política judiciária do Conselho Nacional de Justiça. In: SMANIO, Gianpaolo Poggio; BERTOLIN, Patrícia Tuma Martins (Orgs.). O Direito e as políticas públicas no Brasil. São Paulo: Atlas, 2013, p. 248-268.

SARLET, Ingo Wolfgang. A eficácia dos direitos fundamentais. Porto Alegre: Livraria do Advogado. 1998.

SCHULZE, Clênio Jair. Números de 2019 da Judicialização da Saúde no Brasil. Disponível em: https://emporiododireito.com.br/leitura/numeros-de-2019-da-judicializacaoda-saude-no-brasil. Acessado em: 10 mar. 2020.

SMANIO, Giampaolo Poggio. Legitimidade jurídica das políticas públicas: a efetivação da cidadania. In: SMANIO, Gianpaolo Poggio; BERTOLIN, Patrícia Tuma Martins (Orgs.). $O$ Direito e as políticas públicas no Brasil. São Paulo: Atlas, 2013, p. 03-15.

SOUZA NETO, Cláudio Pereira de. A justicialidade dos direitos sociais: críticas e parâmetros. In: SOUZA NETO, Cláudio Pereira; SARMENTO, Daniel (Coords.). Direitos 
sociais: Fundamentos, Judicialização e Direitos Sociais em espécie. Rio de Janeiro: Lumen Juris, 2010.

STRECK, Lênio Luiz. A necessária constitucionalização do direito: o óbvio a ser desvelado. Revista Direito da UNISC, n. ${ }^{\circ}$ 9/10, 1998.

VASCONCELOS, C. M.; PASCHE, D. F. O Sistema Único de Saúde. In: CAMPOS, G. W. S. et al (Org.). Tratado de saúde coletiva. Rio de Janeiro: Fiocruz, 2006. p. 531-562. 